$\xi=$ 圈

\title{
Large scale electricity storage technology options for smart grid
}

\author{
Surender Reddy Salkuti * \\ Department of Railroad and Electrical Engineering, Woosong University, Daejeon, Republic of Korea \\ *Corresponding author E-mail: salkuti.surenderreddy@gmail.com
}

\begin{abstract}
This paper aims to establish a comparative analysis between various storage techniques available and to evaluate their current impact as well as potential to be employed more effectively in the future. This paper presents the classification of each storage technique on the basis of features, cost, location, mathematical modelling, advantages and disadvantages. This paper shows the energy storage devices behavior to effectively improve the renewable energy sources connected to the utility grid. The paper also identifies the different storage techniques that can be implemented in to a smart grid and a cost benefit analysis of the different storage techniques. The paper exhaustively reviews the functionality of a major sector of smart grid and energy storage. From this paper, it can be observed that the use of energy storage technologies will increase the supply, and balances the demand for energy.
\end{abstract}

Keywords: Smart Grid; Energy Storage; Renewable Energy Sources; Battery; Flywheel; Cost-Benefit Analysis.

\section{Introduction}

The need for energy storage is highlighted by the constant dynamic variations in demand and supply for energy. Energy demand constantly fluctuates on various factors. Factors such as fluctuation of wind supply and the presence of cloud cover will greatly impact the supply of energy obtained from wind and solar energy, respectively [1]. The emergence of new power-generation technologies has brought its own challenges. Many forms of ambient energy, such as solar and the wind, can be harvested to power household appliances directly or be stored in batteries for future use. As such technologies mature, an increasing number of distributed power generation and storage units are installed on the customer's side. A smart grid can be defined as an electrical network that can intelligently integrate the actions of all users connected to it - generators, consumers, and those that do both - in order to efficiently deliver sustainable, inexpensive, and secure electricity [2].

The aim of energy storage is to be able to compensate for periods when demand exceeds supply, and to ensure that no energy goes to waste when supply exceeds demand. The integration of renewable energy to the power grid has increased stability, reliability and efficiency. Renewable energy sources like wind, solar are intermittent in nature. They will create several power quality problems like frequency fluctuations, voltage dip when they are connected to local grid. The major point is that the energy storage techniques are the basis of future smart grid. Without adequate storage techniques, there will be no way to reliably meet the energy demands of the future. The current storage techniques that are explored in this paper are pumped hydro energy storage, flywheels, compressed air energy storage, batteries, superconducting magnetic energy storage, and supercapacitors. Each storage technique will be classified by its features, cost, location, mathematical modelling, advantages and disadvantages. When deciding which storage technique is best to build, it is important to evaluate each, based on its characteristics. And also, using a cost-benefit analysis is also a good way to make a good engineering decision. Having strong numerical evidence based on cost is often a great way to convince the person who will be providing the money [3].

Energy storage may also be provided through flexible load management [4]. Most of the existing storage resources are hydro and pumped storage. However, the growth potential for these resources is much smaller than the need for energy storage necessary to counter the growing net demand variability presented by new wind and solar resources. Various storage technologies are emerging to fill the gap. Battery storage appears to be most to improvements in technology as well as economies of scale. Storage resources tend to make the net demand profile flatter and, as such, are expected to improve the reliability. In addition, most battery storage devices can respond in sub-second time scales [5]. Reference [6] addresses the energy storage for smart grid systems, with a particular focus on design aspects of electrical energy storage in lithium ion batteries. Three energy storage technologies, i.e., sodium-sulfur, vanadium-redox flow batteries, and lithium-ion batteries were examined in Reference [7] along with many other current technologies and chosen due to the potential to operate at grid-scales. Reference [8] introduces the electrical energy storage technology, and it focuses on the research status of energy storage technology in micro grid, distributed generation, new energy power generation, smart grid, energy internet and electric vehicle. The research works regarding the energy storage devices incorporated with power electronics circuit are presented in [9]. An improved strategy for energy storage management and demand-side management based on building energy efficiency technologies and its application to a microgrid based smart grid topology is presented in [10]. Reference [11] presents different types of energy storage technologies experimentally tested in smart grid environment such as electrochemical batteries, ultra-capacitors and kinetic energy storage systems. Reference [12] forms a Virtual Energy Storage System (VESS) and validates that VESS is a cost-effective way to provide the function of energy storage through the utilization of the present network assets represented by flexible demand.

Distributed energy storage is an important element in the smart grid environment and it is essential to understand its operational value to promote investment in this resource. Energy storage can 
be useful in many applications for power system operations, such as voltage support, transmission and distribution upgrade deferral, improving power quality, etc. The importance of energy storage is often overlooked and taken for granted; however, it remains a major technical challenge. Renewable energy must be stored to make it reliable. Wind blows intermittently and as a result, some form of storage is required to compensate for the times when the speed of the wind is moderately low. Solar energy is also not available on cloudy days and during the nighttime, so stored energy must be available to compensate for the loss of sun light. An early solution to the problem of storing energy for electrical purposes was the development of the battery as an electrochemical storage device. The description of various energy storage technologies has been presented next:

\section{Energy storage technologies}

With the increasing importance of energy storage in power system operations, significant efforts have been spent on improving the technical performance of energy storage technologies. These storage technologies include batteries, flywheels, compressed air, pumped-hydro, supercapacitors, and superconducting magnetic energy storage. The storage technologies selected are described next:

\subsection{Flywheel energy storage system}

This storage system is assumed to have a maximum charging and discharging capacity of 20MW. The response time of flywheel system is assumed to be a few seconds. When absorbing energy, the flywheel's motor acts like a load and draws power from the grid to accelerate the rotor to a higher speed. When discharging, the motor is switched into generator mode, and the inertial energy of the rotor drives the generator which, in turn, creates the electricity that is then injected back into the grid [13]. The components of flywheel energy storage system are depicted in Figure 1.

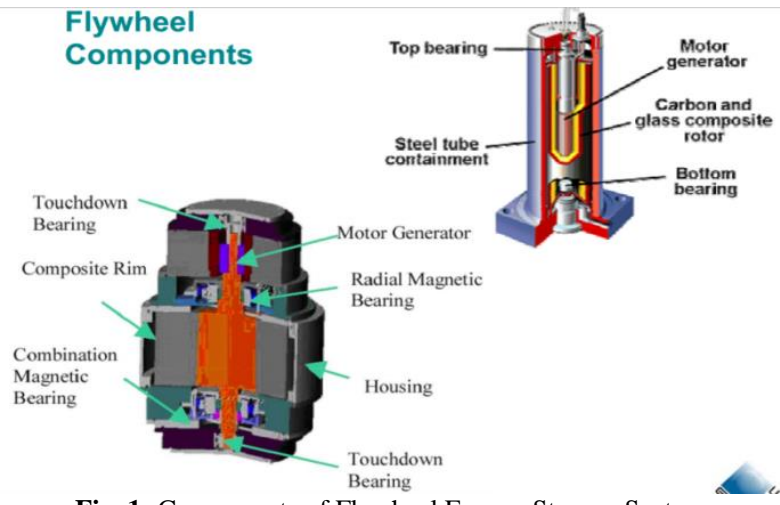

Fig. 1: Components of Flywheel Energy Storage System.

Multiple flywheels may be connected together to provide various megawatt level power capacities. The fly wheel can be expressed mathematically by [13],

$\mathrm{E}_{\mathrm{KE}}=\frac{1}{2} \mathrm{I} \omega^{2}$

Where $\omega$ is angular velocity, I is moment of inertia of mass about the center of rotation. The moment of inertia is the measure of resistance to torque applied on a spinning object. The maximum stored energy is limited by the tensile strength of the flywheel material. With that being stated the maximum specific energy density that can be stored in a flywheel is given by,

$\mathrm{E}_{\mathrm{sp}}=\mathrm{K}_{\mathrm{s}} \frac{\sigma_{\mathrm{m}}}{\rho}$
Where $E_{s p}$ is maximum specific energy density, $\sigma_{\mathrm{m}}$ is maximum strength of flywheel material, $\mathrm{k}_{\mathrm{s}}$ is the shape factor and $\rho$ is the density of flywheel material.

\subsection{Pumped hydro energy storage (PHES) system}

This is the largest-capacity form of grid energy storage available and is reported to account for over $90 \%$ of the bulk storage capacity around, accounting for about 127,000 MW [14]. The PHES system is very straightforward, and can be seen as a modification of regular hydroelectric dams. The operation of PHES system is as follows:

- In periods of low electricity demand, the excess available energy is used to pump water to a higher reservoir (the water turbine is just turned in the reverse direction).

- The pumped water which now possesses gravitational potential energy is stored at a high point in the reservoir till the energy is needed.

- In periods of peak energy demand, water is released from the top of the reservoir and used to turn the turbine to produce electricity.

This helps to raise revenues obtained from a fixed amount of resources as energy is stored at low-cost and made available at a higher cost in periods of peak demand. Figure 2 depicts the typical PHES system [15].

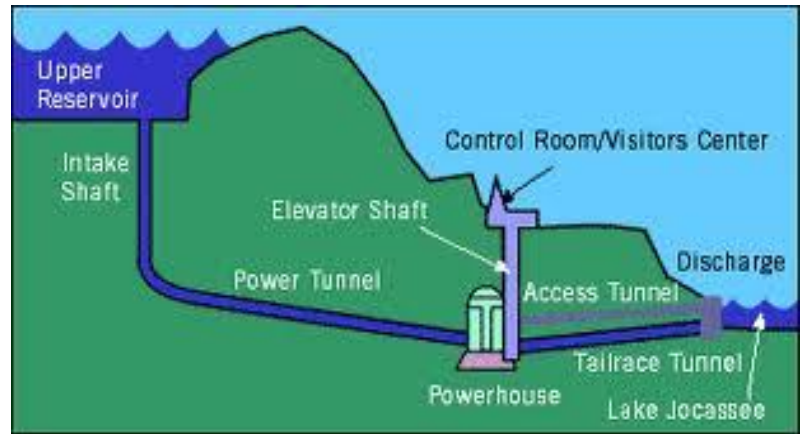

Fig. 2: Schematic Diagram of Pumped Hydro Electric Storage System.

The Electricity Storage Association estimates a range of costs for pumped hydro-electric power to be in the range of $500 \$ / \mathrm{kW}$ to $1500 \$ / \mathrm{kW}$. The important part of this model is the conversion of potential energy of the water as it drops from the source over a height into electric power. The potential energy is expressed as,

$\mathrm{E}=\mathrm{mgh}$

Relation between power to mass flow rate is given by,

$\frac{\mathrm{E}}{\mathrm{t}}=\frac{\mathrm{m}}{\mathrm{t}} \mathrm{gh}$

Therefore, for the hydro-electric power,

$\mathrm{P}=\rho \varphi g h$

$\mathrm{P}=\operatorname{hrgk}$

Where $\mathrm{P}$ is hydroelectric power (in $\mathrm{KW}$ ), $\mathrm{E}$ is energy (in $\mathrm{J}$ ), $\mathrm{m}$ is mass (in $\mathrm{kg}$ ), $\mathrm{g}$ is acceleration due to gravity (in $\mathrm{m} / \mathrm{s}^{2}$ ), $\rho$ is density of water, $\varphi$ is rate of fluid flow and $\mathrm{k}$ is coefficient of efficiency [16].

\subsection{Superconducting magnetic energy storage (SMES) system}

The SMES system involves storing electricity/energy within a magnetic field. The SMES system consists of a superconducting material which essentially has a zero resistance which allows the DC current to pass through freely in its field. The superconductivi- 
ty allows the coil to be wound very compactly, resulting in a high flux density, and hence, a higher specific energy density. However, these superconducting materials exhibit this property only at temperatures beneath their superconducting critical temperature, and hence require cryogenic cooling. The SMES system is charged as current flows through its coils and can store the magnetic energy indefinitely.

This storage system can also be employed to eliminate voltage dips and spikes on the grid. During the spikes, loops of wire take up extra current, and during dips, the loops return the current to the grid. Because the wire has almost no resistance, it stores current with almost no loss [17].

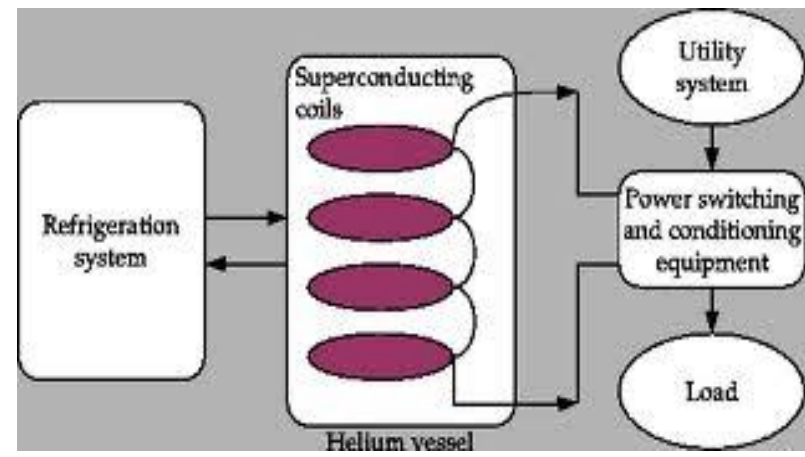

Fig. 3: Features of Superconducting Magnetic energy storage system.

One of the major costs involved in SMES is to obtain the superconducting material. As a result, extensive research is currently being done into discovering the most economical materials to use in the system. The refrigeration system provides another major cost in this system [18]. The model for SMES system has to account for the energy stored in the coils which is given by,

$\mathrm{E}=\frac{1}{2} \mathrm{LI}^{2}$

Where $\mathrm{L}$ is inductance (in $\mathrm{H}$ ), $\mathrm{I}$ is current (in $\mathrm{A}$ ) and $\mathrm{E}$ is energy in (J). Unlike the compressed air and pumped hydropower, the SMES does not require special geographic considerations such as salt caverns or mountains, it can be established in just about any terrain.

\subsection{Supercapacitors}

These are also referred to as ultracapacitors or supercondensers. It is essentially an electrochemical double layer capacitor which consists of two electrodes, a membrane as a separator (which plays the role of the dielectric), and an electrolyte. Similar to regular capacitors, supercapacitors store energy by the separation of charges; but they have a much greater effective surface area along with a much smaller distance of separation, having only a membrane to separate the plates. It should be noted that though the plates are only separated by the membrane, the membrane permits only the flow of ions, and no direct conduction of electricity between the plates. Supercapacitors get charged by extra electricity which helps to push charges onto the plates, leaving them with a net charge. When electricity is needed, the plates are neutralized and charge flows out [19].

Supercapacitors are the capacitors that contain high energy density comparing to actual capacitors They are made up of two electrodes. Ultracapacitors is an energy storage device that stores energy electrostatically by polarising an electrolytic solution. Unlike batteries, no chemical reaction takes place when energy is being stored or discharged and so ultracapacitors can go through hundreds of thousands of charging cycles with no degredation. Energy is stored in ultracapacitor by polarizing the electrolytic solution. The charges are separated via electrode-electrolyte interface [20]. Ultracapacitor consist of a porous electrode, electrolyte and a current collector (metal plates). There is a membrane, which sepa- rates, positive and negative plated is called separator. Figure 4 depicts the principle of operation of Ultracapacitor.

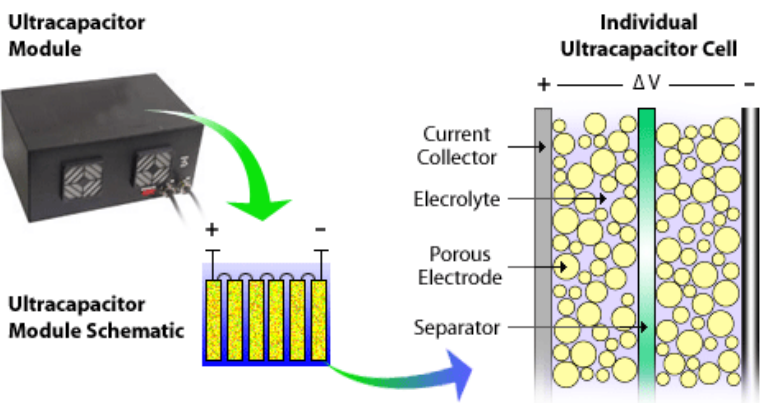

Fig. 4: Principle of Operation of Ultracapacitor.

The modelling of supercapacitor aims to address the amount of energy stored in a capacitor. The capacitance of a capacitor is expressed as,

$C=\varepsilon_{R} \varepsilon_{0} \frac{A}{d}$

Where $\mathrm{C}$ is capacitance, $\mathrm{A}$ is area of overlap of plates, $\varepsilon_{\mathrm{r}}$ is relative permittivity, $\varepsilon_{0}$ is dielectric constant, $\mathrm{d}$ is the separation between the plates. The energy stored in a capacitor is expressed as,

$W_{\text {stored }}=\frac{1}{2} C V^{2}$

Where $\mathrm{W}_{\text {stored }}$ is the energy stored (in $\mathrm{J}$ ).

Supercapacitors can be integrated with regular batteries to create super batteries. This enables faster charging cycles, higher output currents, and also increased efficiency. Supercapacitors are used in electronic applications such as cellular electronics, power conditioning, uninterruptible power supplies. They also used in industrial lasers, in medical equipment, in electric vehicle and for load leveling to extend the life of batteries, and in wireless communication system for uninterrupted service.

\subsection{Storage batteries}

Advances in the power electronics that convert DC power to AC have helped make battery storage systems increasingly reliable [21]. Batteries are made up of several series connected cells connected by an electrolyte for easy electron transfer and electrodes (cathode and anode). Batteries for energy storage can be easily constructed to fit specific needs and they are available in various shapes and sizes. Li-ion batteries are commonly used in plug-in hybrid electric vehicles. These are the vehicles that possess Li-ion batteries in addition to their own combustion engine. The batteries get charged by plugging into electric wall sockets while the combustion engines are smaller than those in regular cars and can be optimized by functioning as a generator that charges the battery. The principle of operation of storage battery is depicted in Figure 5 .

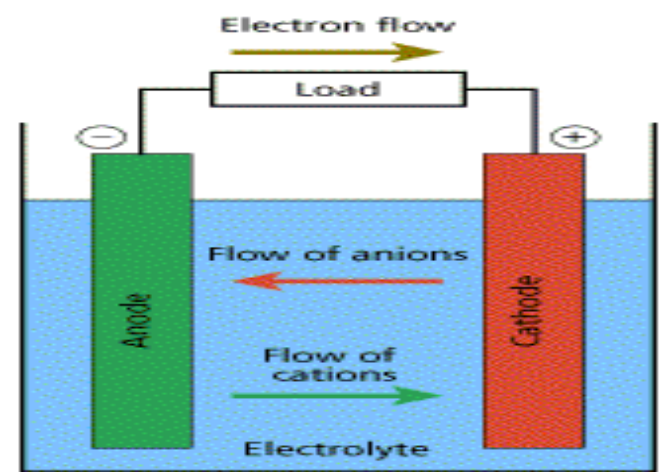

Fig. 5: Operation of Storage Battery. 
It is important to note that batteries are often leak stored energy after charging. The relationship between current, discharge time, and capacity for a lead-acid battery is expressed as,

$t=\frac{Q_{P}}{I^{k}}$

Where QP is capacity when discharged at a rate of $1 \mathrm{~A}, \mathrm{I}$ is the current drawn from battery (in A), $t$ is amount of time (in hours) that a battery can sustain, and $\mathrm{k}$ is a constant

\subsection{Compressed air energy storage (CAES) system}

The basic principle of operation of CAES system is that energy is stored during the off-peak periods of demand in underground formations' or "caverns". These caverns are either created by solution mining or by using an abandoned mine. In the periods of peak demand for power, most often during the day, the stored compressed air is then heated and used to drive a steam turbine. According to the Electric Power Research Institute, the price CAES storage system is about $1000 \$ / \mathrm{kWh}[22]$.

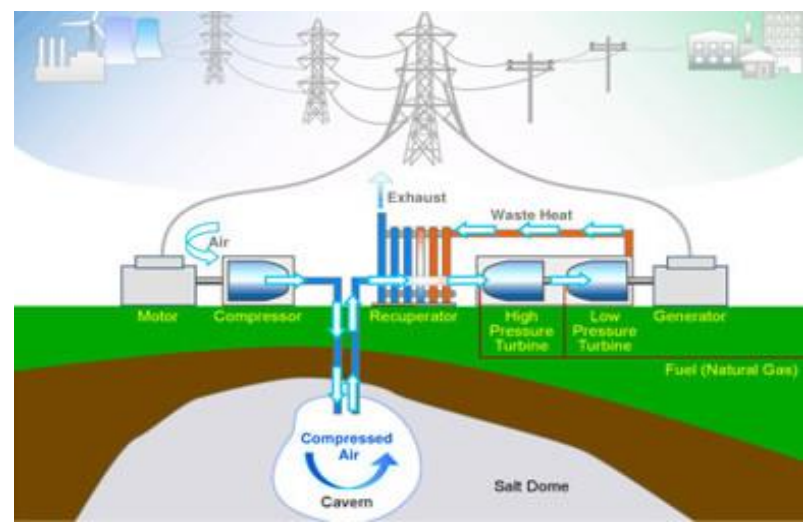

Fig. 6: Schematic Diagram of CAES System.

The modelling for CAES primarily aims to show how the air is compressed, as well as how the compressed air is used to generate the electricity. The compression is expressed by using,

$P_{c}=\frac{1}{n_{c}} m C_{p}\left[\left(\frac{p_{2}}{p_{1}}\right)^{\frac{k-1}{k}}-1\right]$

Where $\mathrm{P}_{\mathrm{c}}$ is the input power to compressor, $\mathrm{n}_{\mathrm{c}}$ is overall efficiency of compressor, $\mathrm{m}$ is the mass flow rate of the air, $\mathrm{p}_{2}$ is pressure at outlet of compressor, $\mathrm{p}_{1}$ is the pressure at inlet of compressor, and $\mathrm{k}$ is the specific heat ratio of air $\left(\mathrm{C}_{\mathrm{p}} / \mathrm{C}_{\mathrm{v}}\right)$. The compressed air also follows the ideal gas laws, and it is expressed as,

$p V=n R T$

Where $\mathrm{p}$ is the absolute volume, $\mathrm{V}$ is volume, $\mathrm{n}$ is amount of gas (mol), $\mathrm{R}$ is ideal gas constant, and $\mathrm{T}$ is absolute temperature. This produces energy to drive the turbine, and it is expressed as,

$W=p_{B} p_{A} \ln \frac{p_{A}}{p_{B}}$

CAES system is still in the infancy stages of exploitation and a lot more can be done. The applications of CAES system include the frequency regulation, auxiliary services and energy arbitrage.

\section{Cost-benefit analysis of different storage technologies}

For a well-rounded cost analysis, the starting point will be the capital costs, i.e. the cost of complete installation of a storage system. These vary widely between the different methods as they are made of different components such as the high temperature super conductor for the flywheel and the low temperature superconductor for the SMES system. Table 1 presents the cost-benefit analysis of different storage methods.

Table 1: Cost-Benefit Analysis for Different Storage Technologies

\begin{tabular}{|c|c|c|}
\hline Storage Technology & Cost & Benefit \\
\hline $\begin{array}{l}\text { Flywheel energy stor- } \\
\text { age }\end{array}$ & $\begin{array}{l}1630 \\
\$ / \mathrm{kW}\end{array}$ & 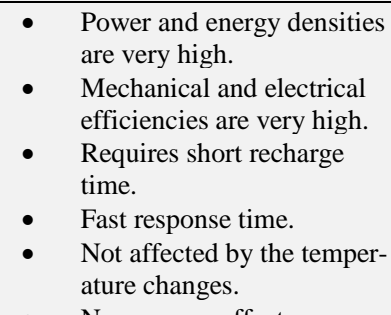 \\
\hline Storage Batteries & $\begin{array}{l}150 \\
\$ / \mathrm{kWh}\end{array}$ & $\begin{array}{l}\text { - } \quad \text { No memory effect. } \\
\text { - } \quad \text { Low self-discharge rate. } \\
\text { meet any requirement. } \\
\text { - Lighter and environmental- } \\
\text { ly friendly. } \\
\text { Reduces the carbon emis- } \\
\text { sions from vehicles. }\end{array}$ \\
\hline Supercapacitors & $\begin{array}{l}50 \\
\$ / \mathrm{kWh}\end{array}$ & $\begin{array}{l}\text { - High power and efficiency. } \\
\text { High rate of charge and } \\
\text { discharge. } \\
\text { - } \quad \text { Low cost per cycle. } \\
\text { - } \quad \text { Mmproved safety. } \\
\text { Materials used have low } \\
\text { toxicity. }\end{array}$ \\
\hline $\begin{array}{l}\text { Pumped Hydro Energy } \\
\text { Storage (PHES) sys- } \\
\text { tem }\end{array}$ & $\begin{array}{l}500 \\
\$ / \mathrm{kWh} \text { to } \\
1500 \\
\$ / \mathrm{kWh}\end{array}$ & $\begin{array}{l}\text { - } \quad \text { High efficiency. } \\
\text { - } \quad \text { Self-sufficient. } \\
\text { Environmental friendly. } \\
\text { Does not produce pollu- } \\
\text { tants. } \\
\text { More developed than other } \\
\text { energy storage techniques. }\end{array}$ \\
\hline $\begin{array}{l}\text { Compressed Air Ener- } \\
\text { gy Storage (CAES) } \\
\text { System }\end{array}$ & $\begin{array}{l}1000 \\
\$ / \mathrm{kWh}\end{array}$ & $\begin{array}{l}\text { any requirement. } \\
\text { Can start up from shut } \\
\text { down condition without the } \\
\text { help of power from a grid. }\end{array}$ \\
\hline $\begin{array}{l}\text { Superconducting Mag- } \\
\text { netic Energy Storage } \\
\text { (SMES) System }\end{array}$ & $\begin{array}{l}2000 \\
\$ / \mathrm{kWh}\end{array}$ & $\begin{array}{l}\text { As the coil has a virtually } \\
\text { zero resistance, it stores } \\
\text { current at almost no loss. } \\
\text { Long service life. } \\
\text { - } \quad \text { No significant negative en- } \\
\text { vironmental impact. } \\
\text { - It has high efficiency for } \\
\text { short duration storage, } \\
\text { making it well-suited for } \\
\text { pulse discharges. } \\
\text { Fast response time. } \\
\text { - } \quad \text { High efficiency. }\end{array}$ \\
\hline
\end{tabular}

From this paper, it can be observed that the appropriate selection of a particular energy storage technology for smart grid applications depends on the system requirements for the type of energy to be stored/used, capacity, lifetime, discharge rate, and the cost. SMES, CAES and pumped hydro storage have large central station energy storage technologies, but they are not well suited to support smart distribution system applications.

\section{Conclusions}

Renewable energy resources (RERs) are intermittent and hence they have a limited contribution to power generation. The solution to this problem can be energy storage technologies, because they can be integrated in the power system structure with different RERs. This paper presents the most relevant properties of energy storage technologies currently being developed in the design of 
power systems. By covering different aspects, in this sense, it describes the most important parameters that characterize the behavior of different technologies and a comparative analysis. SMES system is portable and easily deployable yet very expensive. PHES system is inexpensive and effective, yet has geographic drawbacks as the site needs to be near water. The CAES system has low maintenance and relatively inexpensive but a cavern is needed and the amount of air being compressed could be a potential hazard. Flywheels have a very quick response time as it can absorb energy in a matter of seconds and is inexpensive. Supercapacitors on the other hand are safe, portable, the least inexpensive. These energy storage techniques show great potential to help the RERs and the smart grid to meet the world's growing energy demand. Further research needs to be done on storage techniques to continue to increase the benefits while reducing the associated costs.

\section{Acknowledgment}

This research work is based on the support of "Woosong University Academic Research Funding - 2018".

\section{References}

[1] S. Surender Reddy, James. A. Momoh, "Realistic and Transparent Optimum Scheduling Strategy for Hybrid Power System", IEEE Transactions on Smart Grid, vol. 6, no. 6, (2015), pp. 3114-3125. https://doi.org/10.1109/TSG.2015.2406879.

[2] Available: [Online]. https://www.etip-snet.eu/

[3] P. Du, N. Lu, "Energy Storage for Smart Grids-Planning and Operation for Renewable and Variable Energy Resources (VERs)", Elsevier Inc., (2014)

[4] W.Y. Chiu, H. Sun, H.V. Poor, "Demand-side energy storage system management in smart grid", IEEE Third International Conference on Smart Grid Communications, Tainan, (2012), pp. 73-78 https://doi.org/10.1109/SmartGridComm.2012.6485962.

[5] Y.S. Wong, L.L. Lai, S. Gao, K.T. Chau, "Stationary and mobile battery energy storage systems for smart grids", 4th International Conference on Electric Utility Deregulation and Restructuring and Power Technologies, Weihai, Shandong, (2011), pp. 1-6. https://doi.org/10.1109/DRPT.2011.5993853.

[6] S. Al-Hallaj, S. Wilke, B. Schweitzer, "Energy Storage Systems for Smart Grid Applications", In: Murad S., Baydoun E., Daghir N. (eds) Water, Energy \& Food Sustainability in the Middle East, Springer, Cham, (2017). https://doi.org/10.1007/978-3-319. 48920-9 8.

[7] S.O. Geurin, A.K. Barnes, J.C. Balda, "Smart grid applications of selected energy storage technologies", IEEE PES Innovative Smart Grid Technologies, Washington, DC, (2012), pp. 1-8 https://doi.org/10.1109/ISGT.2012.6175626.

[8] X. Zhou, Z. Fan, Y. Ma and Z. Gao, "Research review on electrical energy storage technology", 36th Chinese Control Conference, Dalian, (2017), pp. 10674-10678 https://doi.org/10.23919/ChiCC.2017.8029057.

[9] S. Sirisukprasert, "Power electronics-based energy storages: A key component for Smart Grid technology", International Electrical Engineering Congress, Chonburi, (2014), pp. 1-7. https://doi.org/10.1109/iEECON.2014.6925979.

[10] D. Tsiamitros et al., "Advanced energy storage and demand-side management in smart grids using buildings energy efficiency technologies”, IEEE PES Innovative Smart Grid Technologies, Europe, Istanbul, (2014), p
https://doi.org/10.1109/ISGTEurope.2014.7028841

[11] E. Ozdemir, S. Ozdemir, K. Erhan, A. Aktas, "Energy storage technologies opportunities and challenges in smart grids", International Smart Grid Workshop and Certificate Program, Istanbul, (2016), pp 1-6. https://doi.org/10.1109/ISGWCP.2016.7548263.

[12] M. Cheng, S. SabahSami, J. Wu, "Virtual Energy Storage System for Smart Grids", Energy Procedia, vol. 88, (2016), pp. 436-442. https://doi.org/10.1016/j.egypro.2016.06.021.

[13] Available: http://en.wikipedia.org/wiki/Flywheel_energy_storage.

[Online].

[14] [Online]Available: http://en.wikipedia.org/wiki/Hydroelectric_energy_storage

[15] Available:[Online]. https://ec.europa.eu/energy/sites/ener/files/energy_storage.pdf
[16] M.T. Al-Nory, M. El-Beltagy, "Optimal selection of energy storage systems", Saudi Arabia Smart Grid, Jeddah, (2015), pp. 1-6. https://doi.org/10.1109/SASG.2015.7449273.

[17] J.X. Jin, X.Y. Chen, "Superconducting Magnetic Energy Storage Modeling and Application Prospect", In: Islam M., Rahman F., Xu W. (eds), Advances in Solar Photovoltaic Power Plants. Green Energy and Technology. Springer, Berlin, Heidelberg, (2016). https://doi.org/10.1007/978-3-662-50521-2_10.

[18] Available: [online] http://www.battcon.com/PapersFinal2002/FurlongPaper2002.pdf

[19] Available: [online]. http://www.howstuffworks.com/environmental/greentech/sustainable/grid-energy-storage $4 . h t m$

[20] Available: [Online] http://www.ultracapacitors.org/index.php?option=com_content\&id $=37 \&$ task $=$ view

[21] Available: [online]. https://www.netl.doe.gov/File\%20Library/research/energy\%20effic iency/smart\%20grid/whitepapers/Energy-Storage_2009_10_02.pdf

[22] Available: [online]. http://phys.org/news188048601.html. 